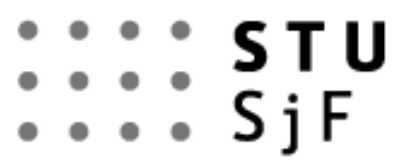

\section{Journal of MECHANICAL ENGINEERING \\ - Strojnícky časopis}

VOLUME 66, NO 2, 2016

pp. $5-12$

\title{
SIMPLE PLANAR TRUSS (LINEAR, NONLINEAR AND STOCHASTIC APPROACH)
}

\author{
FRYDRÝŠEK Karel ${ }^{1}$, JANČO Roland ${ }^{2}$ \\ ${ }^{1}$ Department of Applied Mechanics, Faculty of Mechanical Engineering, VŠB-Technical University of Ostrava, \\ 17. listopadu 15/2172, 70833 Ostrava, Czech Republic, e-mail karel.frydrysek@vsb.cz. \\ ${ }^{2}$ Slovak University of Technology in Bratislava, Faculty of Mechanical Engineering, Institute of Applied \\ Mechanics and Mechatronics, Nám. slobody 17, 81231 Bratislava, Slovakia, e-mail: roland.janco@stuba.sk
}

\begin{abstract}
This article deals with a simple planar and statically determinate pin-connected truss. It demonstrates the processes and methods of derivations and solutions according to $1^{\text {st }}$ and $2^{\text {nd }}$ order theories. The article applies linear and nonlinear approaches and their simplifications via a Maclaurin series. Programming connected with the stochastic Simulation-Based Reliability Method (i.e. the direct Monte Carlo approach) is used to conduct a probabilistic reliability assessment (i.e. a calculation of the probability that plastic deformation will occur in members of the truss).
\end{abstract}

KEYWORDS: planar truss, $1^{\text {st }}$ and $2^{\text {nd }}$ order theories, probability, reliability, nonlinearities, elasticity, plasticity, Simulation-Based Reliability Assessment (SBRA) Method, probabilistic reliability assessment

\section{$1 \quad$ Introduction}

Planar truss structures appear to be the easiest ways of introducing, explaining and solving geometrical and material nonlinearities; see [1], [2], [3] and [4]. In mechanics, for small deformations, tasks of this type (displacements, strains and stresses) can be solved according to the simple $1^{\text {st }}$ order theory or the more precise but more demanding $2^{\text {nd }}$ order theory. However, there are special cases - such as the one presented in this article - which cannot be solved via the $1^{\text {st }}$ order theory.

The $2^{\text {nd }}$ order theory always leads to a nonlinear equation or equations which can be solved via several numerical methods, such the Newton-Raphson Method, the Fixed Point Iteration Method, etc. However, there are some possibilities for simplifying it, for example via a Taylor series or a Maclaurin series. It can then be solved easily and directly with small acceptable error.

If there are some possibilities to obtain simple solutions of complicated problems, the stochastic approach (Monte Carlo Method, Simulation-Based Reliability Assessment (SBRA) Method, probabilistic assessment) can also be easily applied. The SBRA Method is a fairly popular and modern trend in mechanics. Hence, a probabilistic reliability assessment can also be performed. For more information see [4], [5], [6] and [7].

This article presents a solution of a simple statically determinate pin-connected truss consisting of two members (i.e. derivation according to the $1^{\text {st }}$ and $2^{\text {nd }}$ order theories, possible simplifications, error estimation) together with their probabilistic inputs, outputs (histograms) and reliability assessment (i.e. calculating the probability that plastic deformation will occur in members of the truss). 


\section{Simple pin-connected truss consisting of two members (statically determinate)}

The simple pin-connected planar truss consisting of two members is loaded by vertical force F; see Fig. 2.1a. Expressions are derived for angle $\alpha^{*} / \mathrm{rad} /$, normal forces, stresses and elongations in both members and vertical displacement $v_{\mathrm{A}}$ according to the theory of small deformations for $1^{\text {st }}$ and $2^{\text {nd }}$ order analyses. The material of the members is isotropic, linear and elastic. The truss is loaded in a force-controlled manner. The given inputs are force $\mathrm{F} / \mathrm{N} /$, length of members $\mathrm{L} / \mathrm{m} /$, modulus of elasticity $E=E_{1}=E_{2} / \mathrm{Pa} /$ of the material of the members, and area of the cross-sections $A=A_{1}=A_{2} / \mathrm{m}^{2} /$ of the members.
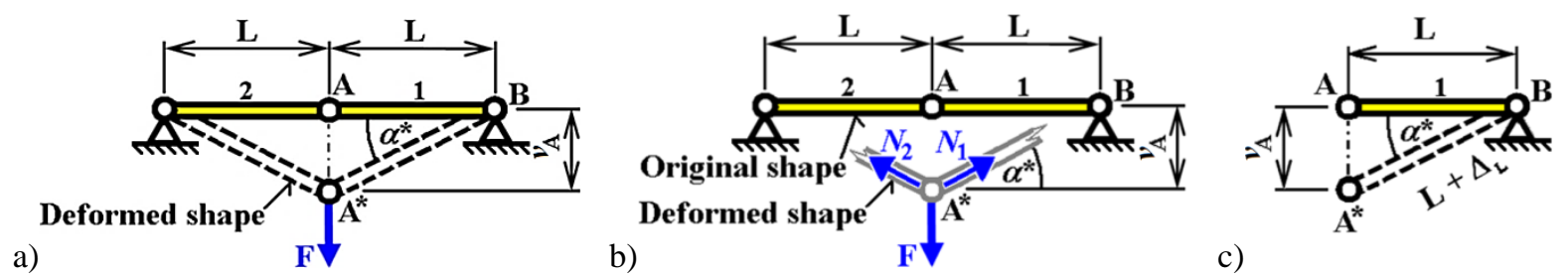

Fig. 2.1 Simple pin-connected truss consisting of two members.

Initially, members " 1 " and "2" of the truss are in an ideal horizontal position, and the deformed shape is caused by added vertical force $\mathrm{F}$ (force-controlled manner of loading). Hence, the angle $\alpha^{*}$ is unknown and is connected with the deformed structure. By applying the method of joints at point " $\mathrm{A}$ " " of the deformed structure, see Fig. 2.1b, the normal forces $N / \mathrm{N} /$ can be derived in both members as

$$
N=N_{1}=N_{2}=\frac{\mathrm{F}}{2 \sin \alpha^{*}}
$$

\begin{tabular}{|c|c|}
\hline $1^{\text {st }}$ order theory & $2^{\text {nd }}$ order theory \\
\hline 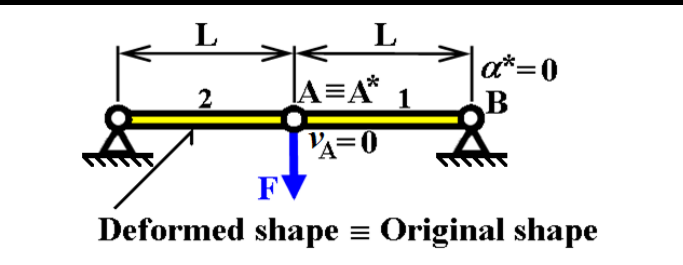 & 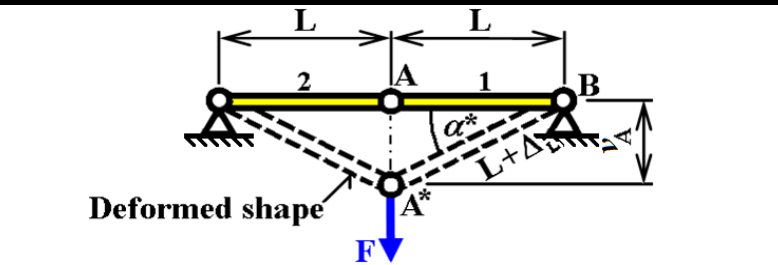 \\
\hline $\begin{array}{c}\alpha^{*}=0 \mathrm{rad}, \\
N=N_{1}=N_{2}=\frac{\mathrm{F}}{2 \sin \alpha^{*}}=\frac{\mathrm{F}}{0}=\infty, \\
v_{\mathrm{A}}=\Delta_{\mathrm{L}}=0 \mathrm{~m}, \quad \sigma=\frac{N}{A}=\infty .\end{array}$ & $\begin{array}{l}\alpha^{*} \cong \operatorname{acos}\left[1-\frac{\mathrm{F}}{2 E \operatorname{Atan}\left(\sqrt[3]{\frac{\mathrm{F}}{E A}}\right)}\right], \\
N=N_{1}=N_{2}=\frac{\mathrm{F}}{2 \sin \alpha^{*}}, \quad v_{\mathrm{A}}=\mathrm{Ltan} \alpha^{*}, \\
\Delta_{\mathrm{L}}=\frac{\mathrm{FL}}{2 E A \sin \alpha^{*}}, \quad \sigma=\frac{N}{A}=\frac{\mathrm{F}}{2 A \sin \alpha^{*}} .\end{array}$ \\
\hline $\begin{array}{l}\text { Undeformable structure. Impossible to } \\
\text { solve via } 1^{\text {st }} \text { order analysis, which gives } \\
\text { incorrect results. }\end{array}$ & $\begin{array}{l}\text { Conclusion: Possible to solve via } 2^{\text {nd }} \text { order } \\
\text { analysis, which gives acceptable results. }\end{array}$ \\
\hline
\end{tabular}

Tab. 2.1 Results of the theory of small deformations $\left(1^{\text {st }}\right.$ and $2^{\text {nd }}$ order theory).

Hence, the solution according to the $1^{\text {st }}$ order theory is given in the first column of Tab. 2.1 (i.e. the simplification that the angular changes are neglected, i.e. $\alpha^{*}=0 \mathrm{rad}$ ), where $\sigma / \mathrm{Pa} / \mathrm{is}$ 
axial stress in the members and $\Delta_{\mathrm{L}} / \mathrm{m} /$ is elongation of the members. However, the results obtained according to the $1^{\text {st }}$ order theory are presenting a solution with absolutely rigid (undeformable) members " 1 " and " 2 ". The $1^{\text {st }}$ order theory gives incorrect results, and it cannot be applied in solutions of such a truss (i.e. no deformations in the truss, infinite stresses etc.).

Therefore, this example must be solved via the $2^{\text {nd }}$ order theory. From the triangle $A, A^{*}, B$ (deformed structure), see Fig. 2.1c, it is possible to derive

$$
\cos \alpha^{*}=\frac{\mathrm{L}}{\mathrm{L}+\Delta_{\mathrm{L}}}=\frac{\mathrm{L}}{\mathrm{L}+\frac{N \mathrm{~L}}{E A}}=\frac{E A}{E A+N}
$$

From eq. (2.1) and (2.2) follows $\cos \alpha^{*}=\frac{E A}{E A+\frac{\mathrm{F}}{2 \sin \alpha^{*}}}$, and after simplification the following nonlinear expression can be derived:

$$
\frac{\mathrm{F}}{2 E A}=\tan \alpha^{*}\left(1-\cos \alpha^{*}\right)
$$

A reasonably good initial estimate of angle $\alpha^{*}$ (i.e. $\alpha_{0}^{*}$ ) can be derived by simplification via a Maclaurin series where $\tan \alpha^{*} \approx \alpha^{*}$ and $\cos \alpha^{*} \approx 1-\frac{\alpha^{* 2}}{2}$. Hence, $\frac{\mathrm{F}}{2 E A}=\alpha_{0}^{*}\left(1-1+\frac{\alpha_{0}^{* 2}}{2}\right)$, from which follows

$$
\alpha_{0}^{*} \approx \sqrt[3]{\frac{\mathrm{F}}{E A}} .
$$

From eq. (2.3) follows $1-\cos \alpha^{*}=\frac{\mathrm{F}}{2 E \tan \alpha^{*}}$, and finally $\alpha^{*}=\operatorname{acos}\left(1-\frac{\mathrm{F}}{2 E \tan \alpha^{*}}\right)$. Thus, the iterative scheme with recursive relation (i.e. the application of the Fixed Point Iteration Method) can be derived as

$$
\alpha_{\mathrm{i}+1}^{*}=\operatorname{acos}\left(1-\frac{\mathrm{F}}{2 E \tan \alpha_{\mathrm{i}}^{*}}\right), \text { for } \mathrm{i}=0,1,2, \ldots .
$$

Hence, with small and acceptable error (for small deformations), this can be written as $\alpha^{*} \cong \alpha_{1}^{*}$, i.e. $\alpha^{*} \cong \operatorname{acos}\left[1-\frac{\mathrm{F}}{2 E \operatorname{Atan}\left(\alpha_{0}^{*}\right)}\right]=\operatorname{acos}\left[1-\frac{\mathrm{F}}{2 E \operatorname{Atan}\left(\sqrt[3]{\frac{\mathrm{F}}{E A}}\right)}\right]$; see the second column of Tab. 2.1 (i.e. the solution according to the $2^{\text {nd }}$ order theory). The correctness of the derived results obtained according to the $2^{\text {nd }}$ order theory can be checked via Pythagoras' theorem, see Fig. 2.1c (i.e. the equation $\left(\mathrm{L}+\Delta_{\mathrm{L}}\right)^{2}=v_{\mathrm{A}}^{2}+\mathrm{L}^{2}$ is satisfied). 
The same results can be derived in many other ways; one of these ways is based on the minimum of total potential energy $\Pi / \mathrm{J} /$ of the truss (i.e. on equation $\frac{\partial \Pi}{\partial \alpha^{*}}=0$ ). Thus

$$
\Pi=U-W_{\mathrm{F}}
$$

where $U=2 \int_{V} \frac{E \varepsilon^{2}}{2} d V / \mathrm{J} /$ is the strain energy (potential energy of strain, i.e. an integral over volume $V / \mathrm{m}^{3} /$ of the members for elastic and isotropic material behaviour and constant crosssection of members, see reference [8]) and $W_{\mathrm{F}}=\mathrm{F} v_{\mathrm{A}} / \mathrm{J} /$ is the work of external force $\mathrm{F}$.

According to Fig. 2.1c, the axial (engineering) strain $\varepsilon / 1 /$ in the members can be derived as

$$
\varepsilon=\frac{\mathrm{L}+\Delta_{\mathrm{L}}-\mathrm{L}}{\mathrm{L}}=\frac{\frac{\mathrm{L}}{\cos \alpha^{*}}-\mathrm{L}}{\mathrm{L}}=\frac{1}{\cos \alpha^{*}}-1
$$

Hence

$$
\Pi=E A L \varepsilon^{2}-\mathrm{FL} \tan \alpha^{*}=\mathrm{L}\left[E A\left(\frac{1}{\cos \alpha^{*}}-1\right)^{2}-\mathrm{Ftan} \alpha^{*}\right],
$$

and the derivative of total potential energy can be performed as

$$
\frac{\partial \Pi}{\partial \alpha^{*}}=\frac{\mathrm{L}}{\cos ^{2} \alpha^{*}}\left[2 E A \sin \alpha^{*}\left(\frac{1}{\cos \alpha^{*}}-1\right)-\mathrm{F}\right]=0 \text {. }
$$

Equation (2.9) is satisfied only for $2 E A \sin \alpha^{*}\left(\frac{1}{\cos \alpha^{*}}-1\right)-\mathrm{F}=0$, from which follows eq. (2.3); the correctness of the acquired expressions in the second column of Tab. 2.1 is proven.

Another interesting ideas and approaches for treatments with nonlinearities are written in [1], [2], [3], [9] and [10]

\section{Probabilistic inputs}

For a solution using a stochastic approach, calculating the probability that plastic deformation will occur and performing a probabilistic reliability assessment, the probabilistic inputs must be defined; see the upper part of Tab. 3.1. Anthill software (i.e. the SBRA Method) was applied in this stochastic modelling; see references [4], [6] and [7].

Five chosen probabilistic inputs (i.e. mutually independent variables) of random type, and their notation via histograms, are shown in Tab. 3.1. These random variables cover real variabilities and fluctuations in technical practice for the truss presented here.

Tab. 3.1 presents all basic statistical information (i.e. minimum, maximum, median and mean values) and histograms. In Anthill software, the histogram "Uniform" means truncated uniform distribution, "n1-05.dis" means truncated normal distribution $\pm 5 \%$, "dead1.dis" means dead load truncated distribution $\begin{gathered}+0 \% \\ -18.9 \%\end{gathered}$, and "a36-m-cont.dis" means yield stress truncated distribution for carbon steel A36. 


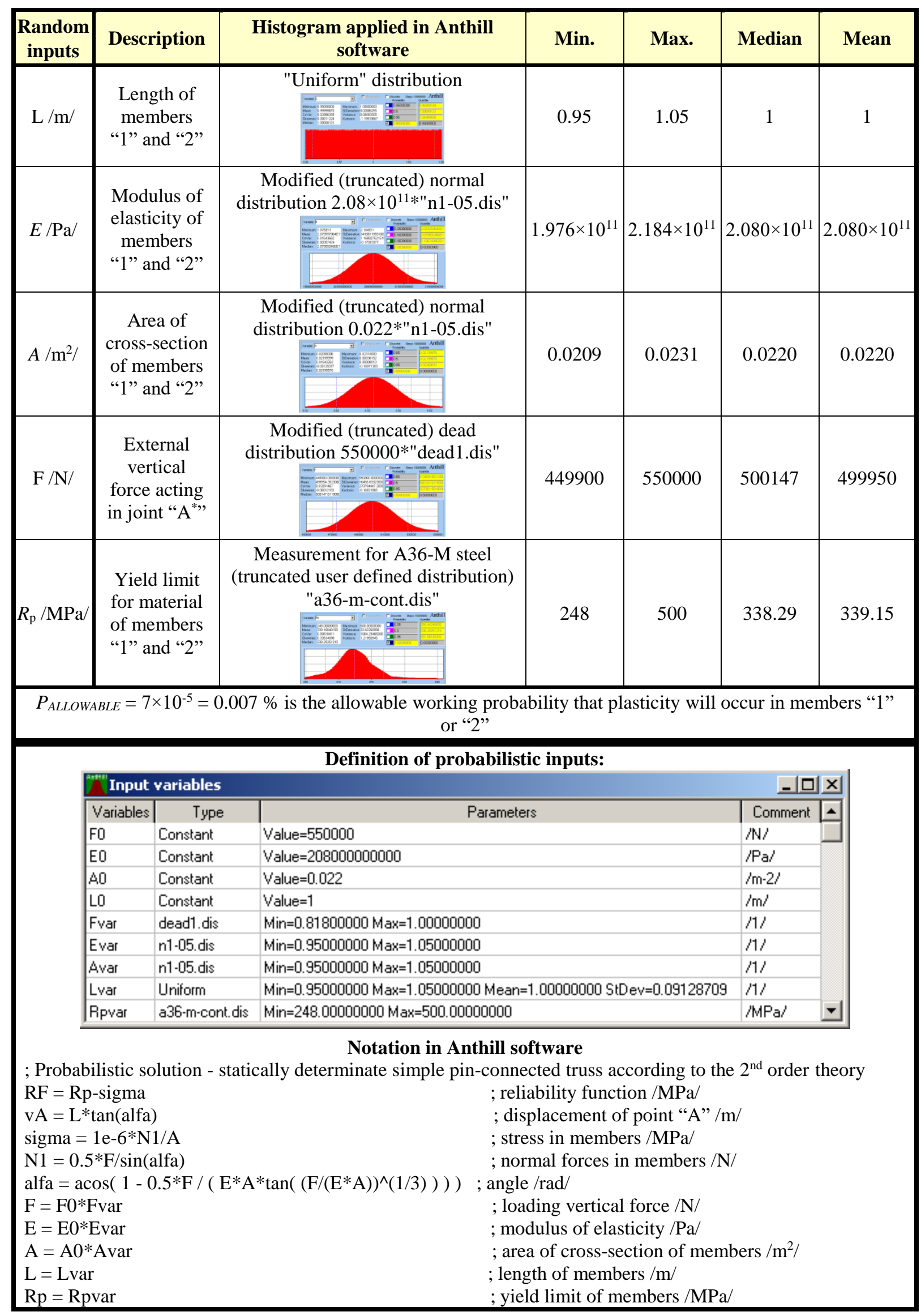

Tab. 3.1 Stochastic inputs and their basic characteristics (simple pin-connected truss) and programming in Anthill software. 


\section{Probabilistic outputs}

The stochastic (probabilistic) results (i.e. stochastic outputs), see Tab. 4.1, can be used for the probabilistic reliability assessment of the solved truss (Anthill software, SBRA Method).

\begin{tabular}{|c|c|c|c|c|c|}
\hline $\begin{array}{c}\text { Stochastic } \\
\text { outputs }\end{array}$ & Description & Min. & Max. & Median & Mean \\
\hline$\alpha^{*} / \mathrm{rad} /$ & Angle in deformed structure $0.0478 \pm 0.0029$ & 0.0449 & 0.0507 & 0.0478 & 0.0478 \\
\hline$v_{\mathrm{A}} / \mathrm{m} /$ & Displacement of point "A" $0.0478_{-0.0048}^{+0.000}$ & 0.0430 & 0.0528 & 0.0478 & 0.0478 \\
\hline$N / \mathrm{N} /$ & $\begin{array}{c}\text { Normal forces in members "1" and "2" } \\
5231785_{-518605}^{+52856} \\
\end{array}$ & $\begin{array}{c}471318 \\
0\end{array}$ & 5760441 & 5231785 & 5231544 \\
\hline$\sigma / \mathrm{MPa} /$ & $\begin{array}{c}\text { Stresses in members "1" and " } 2 \text { " } \\
237.83_{-25.29}^{+26.71} \\
\end{array}$ & 212.54 & 264.54 & 237.83 & 237.84 \\
\hline
\end{tabular}

Tab. 4.1 Stochastic outputs and their basic characteristics (simple pin-connected truss).

Thus, the given stochastic inputs are used to calculate the stochastic outputs $\alpha^{*}, v_{\mathrm{A}}, N$ and $\sigma$ via histograms and distributed functions, as presented in Tab. 3.1. All calculations are performed and evaluated for $\mathrm{N}_{\text {TOTAL }}=10^{7}$ Monte Carlo random simulations.

In this case, the reliability function $R_{F} / \mathrm{MPa}$ can be defined as

$$
R_{F}=R_{\mathrm{p}}-\sigma \text {. }
$$

The reliability function and 2D histogram $\sigma$ vs. $R_{\mathrm{p}}$ are presented in Fig. 4.1. Hence, it is evident that if $R_{F}>0$ (i.e. yield limit $R_{\mathrm{p}}$ is greater than normal stress $\sigma$ ), the stress is below the yield limit (safe loading, no plasticity occurs). Otherwise, if $R_{F} \leq 0$, then plasticity occurs (i.e. an unsafe and undesirable situation).

The probability $P_{f}$ of an unsafe situation (i.e. a situation when $R_{F} \leq 0$ ) is calculated in Anthill software by the expression

$$
P_{f}=P_{\left(R_{F} \leq 0\right)}=\frac{\mathrm{N}_{f}}{\mathrm{~N}_{\text {TOTAL }}},
$$

where $\mathrm{N}_{f}$ is the number of unfavourable states (i.e. states when $R_{F} \leq 0$ ). 


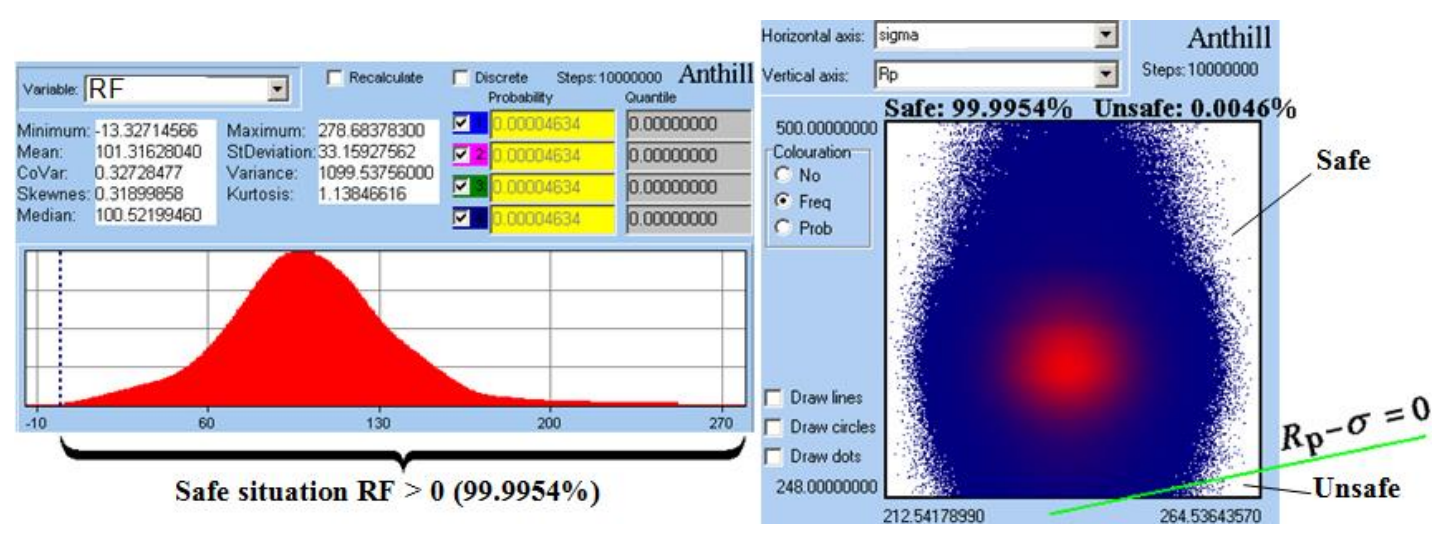

Fig. 4.1 Probabilistic reliability assessment (SBRA Method, Anthill 2.6 software).

From the presented results it is calculated that $P_{f}=4.634 \times 10^{-5}$ (i.e. approx. $0.0046 \%$ of all possible random simulations cause plastic deformations).

Finally, the probabilistic reliability assessment can be performed by checking the inequation

$$
P_{f} \leq P_{A L L O W A B L E} \text {, i.e. } 4.634 \times 10^{-5}<7 \times 10^{-5} .
$$

Inequation (4.3) is fulfilled; the solved truss therefore satisfies the probabilistic reliability condition.

\section{CONCLUSION}

Planar truss structures appear to be the easiest ways of introducing, explaining and solving geometrical and material nonlinearities (in this case, a simple pin-connected and statically determinate truss). The focus is on the understanding, step-by-step derivation, applications, possible simplifications, programming and solution of nonlinear problems which are widely applied mostly by civil and mechanical engineers. The solutions according to the $2^{\text {nd }}$ order theory always lead to a set of nonlinear equations. However, there are possibilities to solve such a task directly via iterative approaches, or to linearize and simplify it (via a Maclaurin series in this case) and then to solve it easily with only small errors. Simplifying a relatively complicated nonlinear set of equations usually enables a relatively easy application. The stochastic approach (direct Monte Carlo Method, Simulation-Based Reliability Assessment (SBRA) Method, probabilistic reliability assessment) is a modern, quite popular trend in mechanics. Hence, the SBRA Method (i.e. stochastic inputs and outputs) was applied in order to determine the probability that plastic deformations will occur in the structure. Finally, a probabilistic reliability assessment was performed by checking the inequation $P_{f} \leq P_{A L L O W A B L E}$ (i.e. the probability that plastic deformation will occur $4.634 \times 10^{-5}<7 \times 10^{-5}$; the solved truss satisfies the probabilistic reliability condition).

This article was supported by the Czech project SP2016/145.

\section{REFERENCES}

[1] Bažant, Z.P., Cedolin, L. Stability of Structures: Elastic, Inelastic, Fracture and Damage Theories. Oxford University Press, New York, 1991 ( $3^{\text {rd }}$ ed., 2010), pp. 1-1011.

[2] Dunaiski, P., Galishnikova, V., Pahl, P. J. Geometrically Nonlinear Analysis of Plane Trusses and Frames. ISBN 9781920109486 , AFRICAN SUN MeDIA, 2009, pp. 1-382. 
[3] Frydrýšek, K. Basic Nonlinear Mechanics of Deformable Bodies in Examples 1. Department of Applied Mechanics, Faculty of Mechanical Engineering, VSB-Technical university of Ostrava, Ostrava, Czech Republic, 2017, (in print).

[4] Frydrýšek, K. Probabilistic Calculations in Mechanics 1 (Pravděpodobnostní výpočty v mechanice 1). Department of Mechanics of Materials, Faculty of Mechanical Engineering, VŠB-Technical University of Ostrava, ISBN 978-80-248-2314-0, Ostrava, Czech Republic, 2010, pp. 1-149 (written in Czech).

[5] Frydrýšek, K. Probabilistic Approaches Applied in the Solution of Problems in Mining and Biomechanics. in ENGINEERING MECHANICS 2011, pp. 151-154, Svratka, 2011, ISBN: 978-80-87012-33-8.

[6] Marek, P., Brozzetti, J., Guštar, M., Tikalsky P et al. Probabilistic Assessment of Structures Using Monte Carlo Simulation Background, Exercises and Software, (2nd extended edition). ISBN 80-86246-19-1, ITAM CAS, Prague, Czech Republic, 2003, pp. 1-471.

[7] Marek, P., Guštar, M., Anagnos, T. et al. Simulation-Based Reliability Assessment For Structural Engineers. CRC Press, Boca Raton, USA, ISBN 0-8493-8286-6, pp. 1-365, 1995.

[8] Frydrýšek, K. Basic Strength and Elasticity of Materials. ISBN 978-80-248-3870-0, Faculty of Mechanical Engineering, VŠB-Technical University of Ostrava, Ostrava, Czech Republic, 2016, pp. 1-264.

[9] Hoschl, C., Okrouhlik, M. Solution of Systems of Nonlinear Equations. Journal of Mechanical Engineering, ISSN 0039-2472, vol. 54, 4, 2003, Slovakia, pp. 197-227.

[10] Jančo, R. Solution of Thermo-Elastic-Plastic Problems with Consistent Integration of Constitutive Equations. Journal of Mechanical Engineering, ISSN 0039-2472, vol. 53, 4, 2002, Slovakia, pp. 197-214. 